\title{
Strategies for Ethics Education with Health Profession Students Before, During, and After Placements
}

\author{
Natalie Pollard* \\ The University of Sydney, Australia \\ Gillian Nisbet \\ The University of Sydney, Australia \\ Belinda Kenny \\ The University of Sydney, Australia \\ Lyndal Sheepway \\ Charles Sturt University, Australia \\ Jodie Jacobson \\ Formerly of the University of Sydney, Australia \\ Emily Tartakover \\ Formerly of the University of Sydney, Australia \\ Andrew Kilgour \\ Charles Sturt University, Australia \\ Lindy McAllister \\ The University of Sydney, Australia
}

\begin{abstract}
Health professionals must practice ethically in order to ensure compassionate and effective client care; function as good interdisciplinary team members; and protect themselves from litigation, and conduct and ethics complaints. Ethics education is a routine inclusion in health profession degrees, but may only be taught in the classroom, divorced from practice. This article argues that students need ethics education before, during, and after practice placements. We suggest that many powerful opportunities for teaching ethics on and after placements are missed or underutilised. We have reviewed the scant evidence, and the literature more broadly, to identify strategies for teaching ethics before, during, and after placements; and have added strategies drawn from our own experiences as clinical educators. We highlight where interdisciplinary perspectives can be added to ethics education. We conclude that more research is needed into approaches and strategies for teaching ethics in different contexts.
\end{abstract}

Keywords: allied health; ethics; ethics education; health professions students; placements

${ }^{\star}$ Corresponding Author: Natalie Pollard, Faculty of Health, Queensland University of Technology,

GPO Box 2434, Brisbane, QLD 4001 Australia Email: natalie.pollard@qut.edu.au 


\section{Journal URL: http://e-learning.coventry.ac.uk/ojs/index.php/pblh}

Pollard, N., Nisbet, G., Kenny, B., Sheepway, L., Jacobson, J. Tartakover, E., Kilgour, A., and McAllister, L. (2018) 'Strategies for ethics education with health profession students before, during, and after placements'. International Journal of Practice-based Learning in Health and Social Care, 6 (2), 95-110

\section{(c) $(\mathrm{i})($} Creative Commons Attribution Attribution-Non-Commercial No Derivatives 4.0 International License (https://creativecommons.org/licenses/by-nc-nd/4.0/ ), which permits unrestricted non-commercial use, distribution, and reproduction in any medium, provided the original work is properly cited and is unaltered. 


\section{Introduction}

In a previous article (Bourne et al. 2013), we discussed the ethical issues that allied health students may encounter on placements, and the ethical tension and ethical distress they may experience. Health professions courses routinely teach ethics, but often this teaching does not occur until later in the courses. In our earlier article, we highlighted the need for courses to prepare students to be ethically aware earlier in their courses, prior to commencing placement; and for students to have strategies at their disposal to manage ethical tensions during placement. We suggested the need for opportunities to further support ethical reasoning and management during placements. We concur with the views of Atwal and Caldwell (2003: 250), that:

Whilst understanding the code of ethics and professional conduct is an important component of an undergraduate course, it is important that this understanding is applied in practice and that occupational therapists are able to recognise, analyse and manage ethical issues.

This application of understanding to practice could be achieved for students of all health disciplines if ethics education were to occur throughout their courses, beginning with preparation for placements, as well as during placements; with further reflection and consolidation of learning about ethics and ethical reasoning in the debrief sessions following their practical experiences. The goal for educators would be to integrate ethics across the curriculum so that ethics is seen as central to professional practice (Elkin 2004).

There is little evidence regarding the most effective ways to educate students about codes of ethics and codes of conduct, or how to recognise and manage ethical issues they encounter on placements. A need to bridge the gap between ethical theory and professional practice dilemmas has led to recommendations for more interactional, experiential ethics education (Numminen, van der Arend, and Leino-Kilpi 2009), and the implementation of problem-based, case-based, and reflective approaches to teaching ethics (Donaldson, Fistein, and Dunn 2010, Geddes, Wessel, and Williams 2004). More recently, information technology has provided online opportunities for students to engage with ethical issues which may arise in health and the community settings (Godbold and Lees 2013). Investigations of students' learning preferences for developing knowledge and skills in ethics have supported interactive approaches. Pettifor, Estay, and Paquet (2002) reported that students rated group discussion of case studies as more helpful, and writing essays and studying for exams as less helpful means for learning ethical reasoning skills. However, the authors cautioned that students demonstrated diverse learning preferences, and recommended a range of educational strategies including group discussion, vignettes, ethics literature, and lectures to develop ethical reasoning skills. Findings by Johnston and Haughton (2007) also suggest that students value lectures and break-out discussion groups over individual problem solving and online activities when they are learning about ethical practice. Such findings suggest that students may benefit from learning opportunities that support the acquisition of the language and theory of ethics, practice with the implementation of reasoning approaches, and a safe environment for discussing challenging personal and professional perspectives of ethics.

Although different approaches to ethics learning and teaching have not been widely investigated, case-based instructional practices have been associated with positive educational outcomes including students' insights into professional roles and obligations (Sharp and Kuthy 2008), interdisciplinary perspectives (Smith et al. 2005), and moral reasoning skills (Self, Wolinsky, and Baldwin Jr. 1989). Furthermore, findings that case studies elicit qualitatively different responses from students, new graduates, and experienced health professionals, demonstrate that cases provide a sensitive measure of ethical reasoning and an effective tool for supporting students to engage in a continuum of ethical reasoning as they acquire knowledge and experience during their courses (Kenny, Lincoln, and Killian 2015). In this article, we draw on the available literature about ethics education for students, as well as our own experiences as educators preparing students for placements, supporting them during 
placements and using their placement experiences during debriefs on return to campus to maximise learning about ethics and ethical reasoning strategies. The strategies we present below are relevant for disciplinary specific learning as well as interprofessional learning situations, and are applicable for students on placements on their own or with peers.

Table 1: A curriculum framework for teaching healthcare ethics

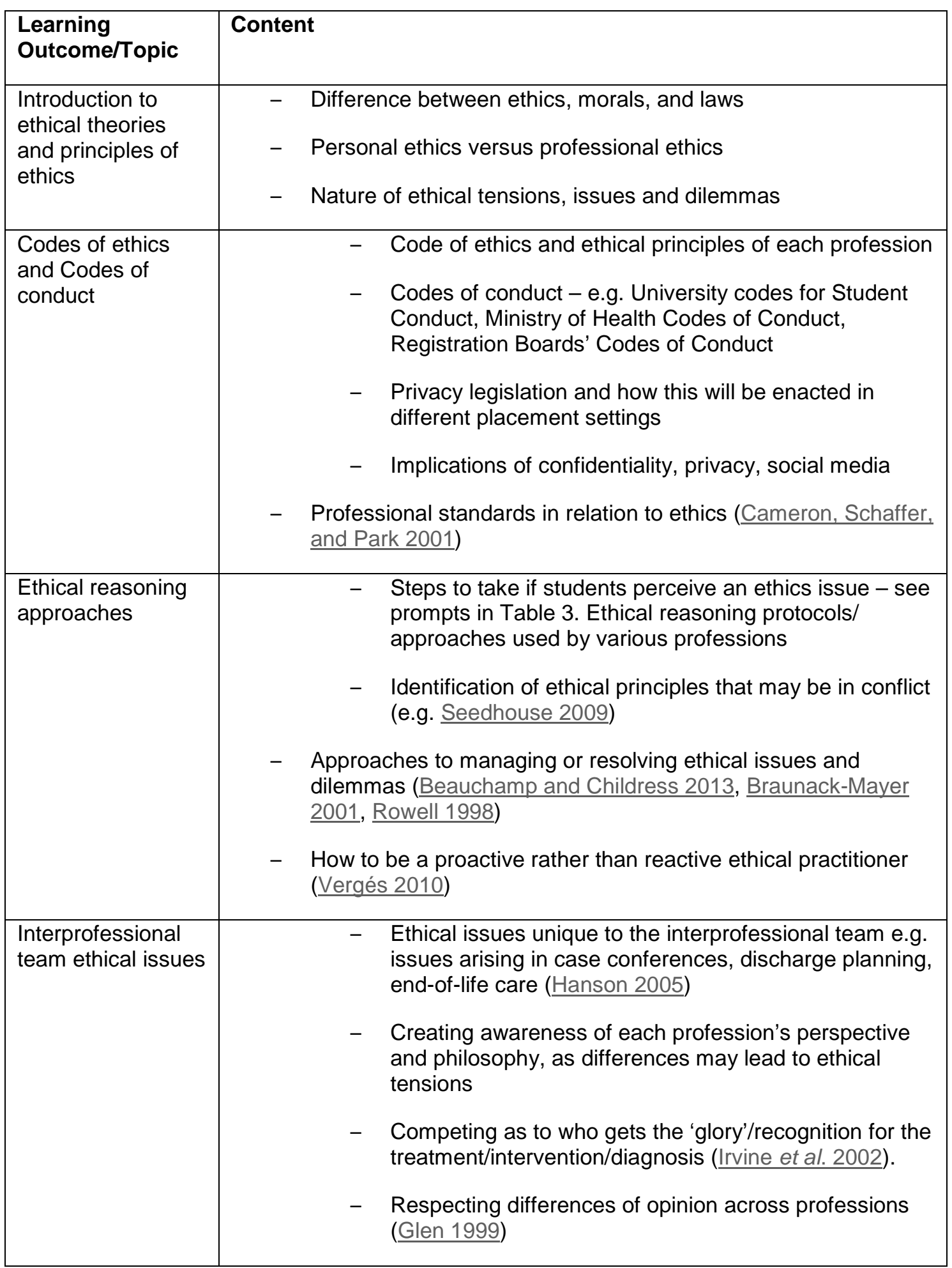




\section{Preparation of students before a placement}

We know that students are faced with ethical issues and dilemmas on placements (Bourne et al. 2013, Cameron, Schaffer, and Park 2001, Geddes, Wessel, and Williams 2004, Kinsella et al. 2008). Therefore, ethics education prior to placements needs to be directly applicable to the realities and issues students will experience in a range of settings (Elkin 2004, Kirklin 2007).

Table 2: Teaching and learning strategies for teaching healthcare ethics

\begin{tabular}{|c|c|}
\hline Strategy & Examples for implementation \\
\hline Reflection & 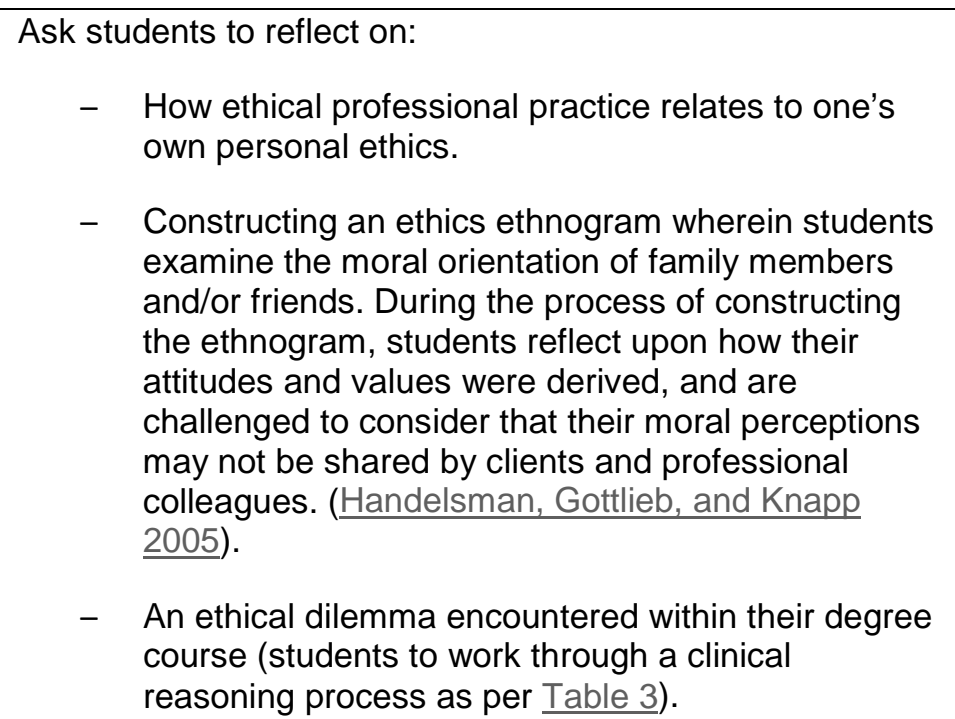 \\
\hline Case Studies & $\begin{array}{l}\text { Best prepared from real experiences - enlist the help of } \\
\text { current health professionals in writing case studies. Also use } \\
\text { previous student reflections, critical incidents, and ethics } \\
\text { research findings to develop authentic case studies. Use } \\
\text { empirically based cases (Bushby et al. 2015, Flatley, Kenny, } \\
\text { and Lincoln 2014, Kulju, Suhonen, and Leino-Kilpi 2013, } \\
\text { Praestegaard and Gard 2013). } \\
\text { Can be written for a specific purpose (e.g. to focus on ethical } \\
\text { tensions, raise privacy issues, or highlight conflicting ethical } \\
\text { principles). } \\
\text { Can be discussed in pairs or as a small group activity - } \\
\text { groups present back to the larger group. } \\
\text { Discussions can be discipline-specific or interprofessional - } \\
\text { depending on context and goal to be achieved. } \\
\text { Case complexity can be adjusted in response to students' } \\
\text { knowledge and experience with ethical issues (Kenny, } \\
\text { Lincoln, and Killian 2015). }\end{array}$ \\
\hline
\end{tabular}




\begin{tabular}{|c|c|}
\hline & $\begin{array}{l}\text { Include a mix of cases that address critical incidents and } \\
\text { ethics in 'every day' professional practice (Liaschenko, } \\
\text { Oguz, and Brunnquell 2006) } \\
\text { Provide students with opportunities to hear, elicit, and } \\
\text { interpret clients' / carers' stories to develop skills in narrative } \\
\text { ethics (e.g. use media stories or films that present different } \\
\text { ethical perspectives / conflict) (Charon and Montello 2002) }\end{array}$ \\
\hline Debate & $\begin{array}{l}\text { Choose a current public health issue as a topic to debate } \\
\text { (e.g. euthanasia, legal age for consuming alcohol) or a } \\
\text { contemporary professional issue including telehealth, new } \\
\text { technology, changing scope of practice, or health care } \\
\text { policy. } \\
\text { Encourage students to debate on the side opposite the one } \\
\text { they have strong opinions about. } \\
\text { Informal debate: can be held as class debate with all } \\
\text { students being assigned to a side of the argument (e.g. } \\
\text { divide room down the middle). Each team is given a set } \\
\text { amount of time in class to prepare their argument. } \\
\text { Structured debate: students allocated to teams of 3-5 } \\
\text { students. Each debate includes short introduction, for and } \\
\text { against presentations, rebuttals, and concluding summary. }\end{array}$ \\
\hline $\begin{array}{l}\text { Flipped Class } \\
\text { Approach } \\
\text { (incorporates a } \\
\text { blended learning } \\
\text { approach) }\end{array}$ & $\begin{array}{l}\text { Use a blended learning approach to introduce theoretical } \\
\text { content to students online (e.g. links to ethical decision- } \\
\text { making protocols, codes of conduct, journal articles). Have } \\
\text { short quizzes to check students' engagement with online } \\
\text { material. Establish a discussion board to encourage critical } \\
\text { thinking prior to face-to-face class. } \\
\text { Face-to-face class time is used for discussion and debate - } \\
\text { online learning used to inform discussion on ethical } \\
\text { dilemmas, analyse case studies and debate topical issues. }\end{array}$ \\
\hline $\begin{array}{l}\text { Audience Response } \\
\text { Systems }\end{array}$ & $\begin{array}{l}\text { Useful to gauge level of understanding of students at any } \\
\text { point in time within a class (formative feedback), and to } \\
\text { generate discussion within the class. } \\
\text { Polling before or after a debate to demonstrate a change in } \\
\text { critical thinking about debate topic (Garrity 2013). }\end{array}$ \\
\hline Simulation & $\begin{array}{l}\text { One example is the 'hot seat' or 'gold fish bowl' technique } \\
\text { where, in groups of 8, one student interacts with a } \\
\text { standardised patient and the rest of the group observes } \\
\text { (Brondani and Rossoff 2010). } \\
\text { Role plays. } \\
\text { Technology supported (e.g. Seedhouse's Value Exchange) } \\
\text { (Godbold and Lees 2013). }\end{array}$ \\
\hline
\end{tabular}


Table 1 provides a listing of suggested ethics curricula topics and content to assist educators to introduce ethics education into curricula prior to students attending placements. Suggested topics include: introducing ethical theories and models (Cameron, Schaffer, and Park 2001), professional standards and codes of ethics and conduct, approaches to ethical reasoning (Kenny 2015), and interprofessional team ethical issues (Banks 2010). This framework will prepare students with knowledge of expected ethical practice, and skills to demonstrate ethical behaviours on placement.

Table 2 presents a range of teaching and learning strategies that can be used to address the topics listed in Table 1. To engage students and maximise learning outcomes, ethical examples from practice should be provided. For example, case studies or vignettes based on real experiences can help to contextualise ethical dilemmas for students. Cases presented in the interprofessional context need to have relevance for all professions (Spike and Lundstroth 2016), and require collaborative development to ensure multiple perspectives are incorporated. Cases should provide students with opportunities to consider ethics issues from the perspectives of other disciplines as well as their own. Debates and discussions increase awareness of professional roles and ethical reasoning (Garrity 2013). A flipped classroom approach, using blended learning strategies, provides opportunities to introduce theoretical content to students in an interactive and engaging way (Donaldson, Fistein, and Dunn 2010).

Fundamental to the suggested teaching and learning strategies is reflection. Reflective practice is critical for clinical learning, and effective and safe clinical care (Dunn and Musolino 2011, Mann, Gordon, and MacLeod 2009), and we suggest is a key component of ethical practice. Reflection is core to ethics education and in Table 3 , we outline a process that can be used to identify ethical issues in case studies during ethics education prior to placement. The questions in Table 3 may be used to facilitate students' deeper understanding of ethical issues in professional practice.

Table 3: Assisting students to identify the ethical issue

What is the situation?

Who is involved?

How does the situation relate to my discipline's code of ethics / code of conduct?

How does the situation relate to codes of ethics / codes of conduct of other disciplines I am interacting with regarding this client / situation?

What are the ethical principles at stake / in conflict?

What are the potential impacts on quality of client care?

Who can I talk with about this?

Do I have an opportunity to talk it through?

By providing students with knowledge of ethics codes and strategies to identify and manage ethical dilemmas, students will have a sound foundation for ethical practice during placements.

\section{During placement}

Students on clinical placement are exposed to a myriad of ethical issues, each presenting an ideal learning opportunity. However, many of these learning opportunities are missed for a 
range of reasons. From a clinical educator perspective, it could be that ethical practice is such an ingrained and implicit part of daily practice that it is difficult for educators to recognise ethics learning opportunities, and articulate them for students. Alternatively, teaching around ethical practice may be considered less important compared with technical skill development, with ethics knowledge considered something that is developed 'on the job'. Furthermore, educators may not have consciously considered ethical practice as something that students require support to develop. For other educators, limited confidence in their ability to discuss ethical issues may be a barrier to discussing ethics with students.

From a student perspective, safe spaces, time, and resources to raise, actively discuss and reflect on ethical dilemmas can be limited on placement. There is also an issue of value students place on learning about ethical practice compared with 'hard core' technical skills. For some students, ethics is seen as 'common sense', even though we know many experience ethical uncertainty and distress (Bourne et al. 2013). Clearly, strategies are required to assist clinical educators and students to address ethical issues that arise during clinical placements, and to use these as rich, authentic learning opportunities.

\section{Strategies for building ethics education into clinical placement $I$ supervision}

\section{Facilitated debriefs}

Ethical issues require time to work through in an educationally meaningful way. We recommend dedicated time be built into clinical placement timetables to discuss ethical issues. This may be half an hour at the end of each week where all students on placement at a particular site come together for a facilitated debrief. This may or may not involve the clinical educator as the facilitator. For example, another member of the department or interdisciplinary colleague could take this role. This approach is beneficial when the clinical educator lacks confidence in discussing ethical issues, as it provides an opportunity to learn by watching and working alongside someone else. It also provides an alternative person for students to discuss ethical issues with. This is particularly important if the ethical issue involves the clinical educator (Bourne et al. 2013). Group debriefs provide opportunities for peer learning. Through discussion, students gain insights into diverse ethical issues, hear different perspectives and management approaches, and collaboratively identify strategies to manage ethical problems. If these debrief sessions include students from a range of health professions, there is an added educational advantage of interprofessional learning about ethics and management approaches.

Clinical educators, however, must be mindful that sometimes students may prefer to debrief individually. Students should be reminded that this option is available, and advised who to approach for a confidential discussion if there are ethical concerns about their educator. For some clinical placements, there may be one student on placement, limiting opportunity for peer learning. However, this should not inhibit discussion around ethical issues. We recommend an online system of sharing ethical issues arising during clinical placement. However, our experience highlights the need for moderation of online discussion boards by an experienced facilitator to ensure students comprehensively work through issues, and that sensitive, complex, ethical issues are managed appropriately and confidentially. Marks can be assigned to online discussion to encourage both participation and quality of discussion, or participation in an online ethics forum could be a mandatory requirement for placements.

\section{Structuring the debrief session - guided reflection}

It is important that clinical educators prepare students for debrief sessions. Prior to the first session, it is useful to set 'ground rules'. This ensures greater alignment between student and clinical educator expectations of the session. Examples of useful ground rules are 'discussions are kept confidential amongst the group unless legal issues are raised; listen to and respect the perspective of the individual'. Students should also be provided with examples of types of 
experiences that could be discussed at these sessions (Table 4). However, having students work through actual situations they have experienced, increases the authenticity and relevance of the learning.

Table 4: Examples of student experiences suitable for discussion at debrief meetings

1. The patient was accompanied into the $x$-ray room by her husband. I confirmed the patient's identity and reason she was presenting for the exam. As she was of childbearing age, I questioned her pregnancy status. She indicated that she may be pregnant. The department protocol was to then obtain a blood test in order to confirm pregnancy and review the requirement of an x-ray. I advised the patient of this requirement and the husband became quite vocal and aggressive, and began putting pressure on the patient to refuse the blood test. His behaviour made me feel uncomfortable as I believed it was the patient's right to make the decision that is best for her and her unborn child. The husband's behaviour was presenting an ethical dilemma.

2. I began to position my patient, and was suddenly met with fierce opposition from my physiotherapy supervisor. I proceeded to explain my reasoning for what I was doing, which was consistent with what we had recently learnt at University. This explanation was again met with opposition. My supervisor stated that she could not comprehend my reasoning, and that what I was doing was unnecessary and time-consuming. I felt humiliated and confused as to what I was doing wrong as I was of the understanding it was best practice.

Reflective practice models are widely used by clinical educators when facilitating debrief sessions because students are specifically asked to engage with their thoughts or feelings about a situation they have experienced. Figure 1 displays our reflective model which clinical educators may use to facilitate student reflection on ethical issues. The model begins with students describing an experience or situation that surprised, amazed or concerned them. Experiences can elicit a range of emotions including uncertainty, concern, puzzlement, anger, anxiety or distress. Students then describe how it made them feel. The second part to the model asks students to tease out the components eliciting such emotions, and also reflect on their thoughts and actions. For discussions around ethical issues, this might involve asking why such actions occurred; what it was that brought on the strong emotional reaction; and what ethical principles were involved or were in conflict. The third part to the model asks students to reflect on how this experience has changed their perspective, and actions they would now take if faced with a similar situation. For the ethical issues debrief session, this step commits students and educators to actions that will address the ethical issue raised.

\section{Articulating ethical decision making processes}

Clinical educators are role models for their students. Students observe and often mimic their work practices - including ethical practice. However, we argue that observation is not enough. For deeper learning around ethical practice, we encourage clinical educators to 'talk aloud' and articulate with students their thinking around ethical issues. Through this process, students begin to understand and appreciate how experienced clinical educators process situations. These 'real time' discussions help students relate the learning to their own developing ethical practice. The script in Table 3 can be used as a guide for clinical educators to articulate with students their ethical thinking, reasoning, and decision making. We know that experienced clinicians use different approaches to ethical reasoning compared with new graduate professionals and students (Kenny, Lincoln, and Balandin 2010). Where students apply structured models to resolve ethical conflict, clinical educators integrate narrative ethics and 
draw upon previous case experiences to respond to ethical concerns. Articulating ethical reasoning provides opportunities for students to develop insight into clients' perspectives, and to benefit from clinical educators' experiences managing ethical dilemmas in the workplace.

Figure 1: A model to promote students' reflective practice on ethical issues

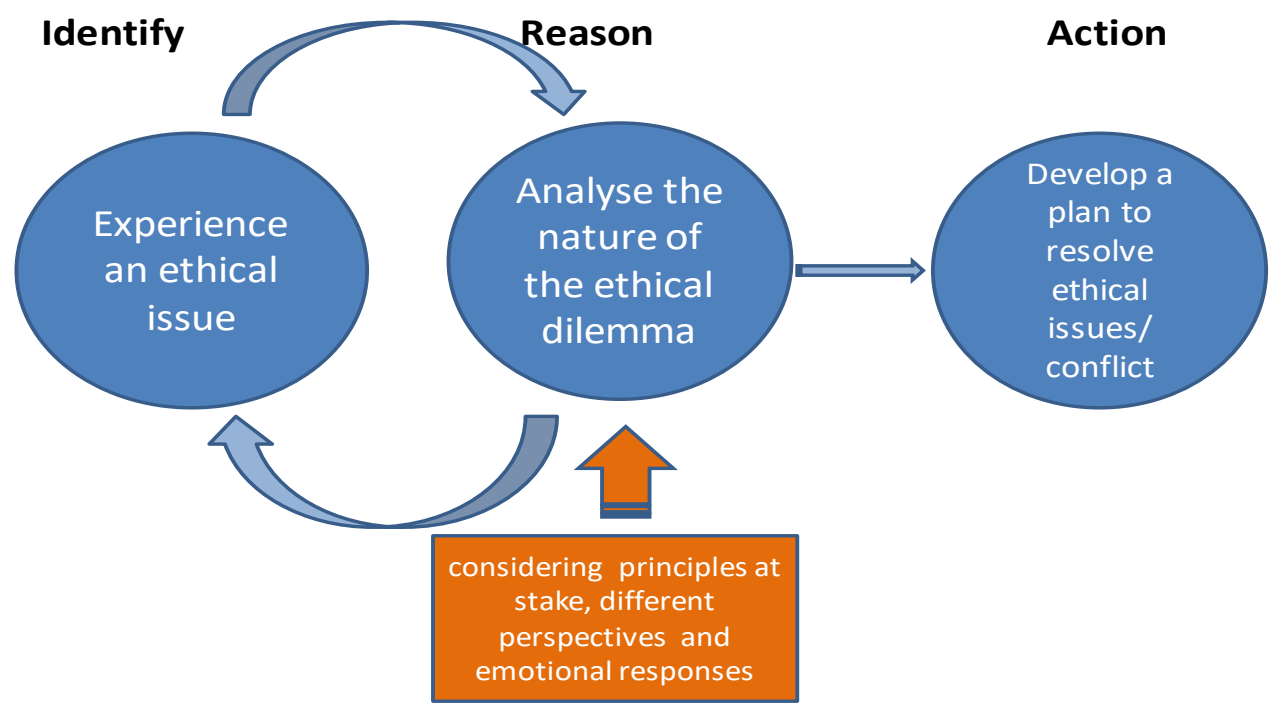

\section{Critical incident case study presentation}

Students on placement are sometimes required to present a critical incident or case study of a patient / client whose care they have been involved with. Students should be encouraged to highlight any ethical issues when presenting. This could readily be achieved by including a question in the case study guidelines that specifically ask students to consider any ethical implications, and to reflect on this experience using the model of reflective practice outlined in Figure 1.

Some disciplines require students to submit a written critical incident or case study specifically on an ethical dilemma experienced. Students should be given structure to assist them in completing this task. Students can use the steps outlined in Table 3 to assist in identifying an ethical dilemma that occurred during placement. This information is then used to write a reflective case study using the reflective prompts outlined in Table 5.

Table 5: Reflective Prompts

What ethical issues does this reflection raise?

How does this fit within your own developing framework of ethical practice?

How does this fit with your professional Code of Conduct/Code of Ethics?

How were these ethical issues addressed or managed?

What could/would you do differently in a similar future situation? 


\section{Written reflections}

Many healthcare degree courses require students to submit written reflections on their clinical placement experiences, for example through regular online journaling. One way of incorporating learning around ethical issues would be to include reflective prompts to specifically draw out ethical issues (Table 5). It may also be helpful for students to write the reflections from the perspective of different people who are involved in the dilemma (e.g. client, carer or health professional from another discipline). Over time, students may reflect on how their ethical reasoning has progressed and developed. However, processes need to be in place to ensure confidentiality of information submitted; restrictions on who views the information, for example only the university educator; and how individual feedback is provided to students.

Table 6: Examples of ethical dilemmas during clinical placement

(1) When it is the placement supervisor that is involved:

Scenario

You are a student occupational therapist on clinical placement observing your supervisor with a client. The client is elderly and becoming agitated. Your supervisor is unable to perform all of the tests required for the assessment. Rather than documenting this, she reports the incomplete tests as 'normal' stating to you that 'they were normal last time and wouldn't have changed much this time.'

(2) When other members of staff are involved:

\section{Scenario}

You are a speech pathology student on placement in a neurology ward of a large teaching hospital. The client under your care for impaired swallowing complains about the 'roughness' in treatment by one of the members of the interprofessional team. The client becomes noticeably distressed when relaying her experiences and states she feels 'unsafe' with that particular health professional, who is a senior member of the interprofessional team. This is not the first time a client has complained to you about this health professional whilst you have been on the ward.

(3) When the patient is involved:

Scenario

You are a student radiographer about to perform an examination under the supervision of your supervisor. After introducing yourself to the client and escorting them from the waiting room to the x-ray room, your client appears greatly offended. She informs you that she thought you were a clerk who was responsible for transporting patients between reception and the x-ray room, and that you would not be performing the $\mathrm{x}$-ray. The client advises you that she does not give consent for you to perform the examination, and will not provide you with a reason.

Note: Whilst scenarios may mention particular health professions, all scenarios can be generalised to other professions.

\section{Class discussion boards / wikis / blogs.}

'My Class discussion board felt like a life-line during my clinical placement' (Student feedback on their placement 2013). 
Structured online learning opportunities using blogs and wikis on the class discussion boards are becoming an avenue for peer learning (Maidment 2006). During a student's placement, relevant posts from classmates can present informative discussion material and become a useful learning and reflective resource, particularly for those in a rural location or on a solo placement. Discussion boards should be moderated by an experienced facilitator, with clear structure and guidelines regarding confidentiality, respectful communication, and feedback provided to students. However, despite these formal avenues of communication, students tend to make use of more informal communication channels such as Facebook class groups. The disadvantage of such channels is that discussions are not moderated by an academic and hence privacy breaches may occur, and inaccurate information or perceptions may remain unresolved. Furthermore, anxieties can be raised unnecessarily within such sites if a student is presenting negative opinions that are not appropriately challenged by peers.

\section{What to do when ethical dilemmas arise during placement}

Ethical dilemmas can arise for students on clinical placement through a number of situations and contexts. Table 6 presents other typical scenarios which can be worked through following reflective steps we have outlined previously.

\section{Post placement strategies}

A post-placement reflective exercise during a structured debriefing session at university is a powerful and effective learning tool in assisting students to develop ethical reasoning. Students could utilise the same case study both before and after placement to compare and contrast how their views on the ethical dilemma may or may not have changed following placement. Student perceptions can be obtained in various ways, for example via electronic survey or audience response systems enabling the students' post-placement answers to be compared to their preplacement answers. An exploratory discussion can then be facilitated regarding why their opinions / actions might have (not) changed.

Guided systematic reflections on placement issues allow students to obtain an integrated and meaningful view of their experiences (Pasco, Bay, and Courtney 2010), and we argue that these reflections should include ethical tensions students experienced during clinical placement. The discussions can be structured around a reflective process as outlined in Figure 1. Garrity (2013) recommends specific areas for students to consider in these reflections including:

- Describing what happened (including, who was involved and what their opinions / roles were);

- What surprised or concerned them, and how this made them feel;

- What was involved in their decision making process and why (including which ethical principles they considered);

- How did the issue get addressed and what was the result;

- What would they do if the same situation were to occur again (what would they do the same, what would they do differently and why);

- What did they learn from the experience.

If students are hesitant to share their thoughts or experiences, or have difficulty identifying or articulating specific examples; then utilising a situation that they might have seen their placement supervisor involved in, or the case studies we have provided, could be used as a starting point. These can also be developed into role plays which give the students an opportunity to simulate real experiences which require ethical management. Volunteers or medical actors (standardised patients) can be utilised to play the role of the patient / client / staff member / supervisor for this exercise. Students who are not directly involved can critically observe and contribute to a discussion regarding options to manage the ethical issue, especially if resolution of the issue is not possible, focussing on the process and the ethical principles involved, rather than specific solutions (Hill, Davidson, and Theodoros 2010). 


\section{Conclusion}

Students experience ethical concerns and distress on placements, and need to be prepared for placements with enhanced ethical awareness and a set of strategies at their disposal to manage ethical concerns. Not only will awareness and strategies support their learning, they will also enhance patient / client care. In this article, we have drawn on the available literature and limited evidence about effective approaches to health students' ethics education as well as our own experiences as educators in university and clinical placement / fieldwork settings. We have suggested a range of content for ethics education, and learning and teaching strategies appropriate for use before, during, and after placements. The strategies can be used in a range of discipline-specific or interdisciplinary placement and teaching contexts. In presenting these, we acknowledge that research is needed to evaluate the efficiency and impact of these strategies. 


\section{References}

Atwal, A. and Caldwell, K. (2003) 'Ethics, occupational therapy and discharge planning: Four broken principles'. Australian Occupational Therapy Journal, 50, 244-251 https://doi.org/10.1046/j.1440-1630.2003.00374.x

Banks, S. (2010) 'Interprofessional ethics: A developing field? Notes from the Ethics \& Social Welfare Conference'. Ethics and Social Welfare, 4 (3), 280-294 https://doi.org/10.1080/17496535.2010.516116

Beauchamp, T.L. and Childress, J.F. (2013) Principles of Biomedical Ethics. 7th edn. New York: Oxford University Press

Bourne, E., Sheepway, L., Charlton, N., Kilgour, A., Blackford, J., Alam, M., and McAllister, L. (2013) 'Ethical awareness in allied health students on clinical placements: Case examples and strategies for student support'. Journal of Clinical Practice in SpeechLanguage Pathology, 15 (2), 94-98

Braunack-Mayer, A. (2001) 'Casuistry as bioethical method: An empirical perspective'. Social Science \& Medicine, 53 (1), 71-81 https://doi.org/10.1016/S0277-9536(00)00314-2

Brondani, M.A. and Rossoff, L.P. (2010) 'The "hot seat" experience: A multifaceted approach to the teaching of ethics in a dental curriculum'. Journal of Dental Education, 74 (11), $1220-1229$

Bushby, K., Chan, J., Druif, S., Ho, K., and Kinsella, E.A. (2015) 'Ethical tensions in occupational therapy practice: A scoping review'. British Journal of Occupational Therapy, 78 (4), 212-221 https://doi.org/10.1177/0308022614564770

Cameron, M.E., Schaffer, M., and Park, H.-A. (2001) 'Nursing students' experience of ethical problems and use of ethical decision-making models'. Nursing Ethics, 8 (5), 432-447

Charon, R. and Montello, M. (eds.) (2002) Stories Matter: The Role of Narrative in Medical Ethics. London: Routledge

Donaldson, T.M., Fistein, E., and Dunn, M. (2010) 'Case-based seminars in medical ethics education: How medical students define and discuss moral problems'. Journal of Medical Ethics, 36 (12), 816-820 https://doi.org/10.1136/jme.2010.036574

Dunn, L. and Musolino, G.M. (2011) 'Assessing reflective thinking and approaches to learning'. Journal of Allied Health, 40 (3), 128-136

Elkin S.A. (2004) 'The integration of ethics teaching in the therapy professions'. Focus on Health Professional Education: A Multi-Disciplinary Journal, 5 (3), 1-6

Flatley, D.R., Kenny, B.J., and Lincoln, M.A. (2014) 'Ethical dilemmas experienced by speechlanguage pathologists working in private practice'. International Journal of SpeechLanguage Pathology, 16 (3), 290-303 https://doi.org/10.3109/17549507.2014.898094

Garrity, M.K. (2013) 'Developing nursing leadership skills through reflective journaling: A nursing professor's personal reflection'. Reflective Practice: International and Multidisciplinary Perspectives, 14 (1), 118-130 https://doi.org/10.1080/14623943.2012.732940 
Geddes, E.L., Wessel, J., and Williams, R.M. (2004) 'Ethical Issues identified by physical therapy students during clinical placements'. Physiotherapy Theory and Practice, 20, 17-29 https://doi.org/10.1080/09593980490425076

Glen, S. (1999) 'Educating for interprofessional collaboration: Teaching about values'. Nursing Ethics, 6 (3), 202-213 https://doi.org/10.1177/096973309900600303

Godbold, R. and Lees, A. (2013) 'Ethics education for health professionals: A values based approach'. Nurse Education in Practice, 13 (6), 553-560 https://doi.org/10.1016/j.nepr.2013.02.012

Handelsman, M.M., Gottlieb, M.C., and Knapp, S. (2005) 'Training ethical psychologists: An acculturation model'. Professional Psychology: Research and Practice, 36 (1), 59-65 https://doi.org/10.1037/0735-7028.36.1.59

Hanson, S. (2005) 'Teaching health care ethics: Why we should teach nursing and medical students together'. Nursing Ethics, 12 (2), 167-176 https://doi.org/10.1191/0969733005ne773oa

Hill, A.E., Davidson, B.J., and Theodoros, D.G. (2010) 'A review of standardized patients in clinical education: Implications for speech-language pathology programs'. International Journal of Speech-Language Pathology, 12 (3), 259-270 https://doi.org/10.3109/17549500903082445

Irvine, R., Kerridge, I., McPhee, J., and Freeman, S. (2002) 'Interprofessionalism and ethics: Consensus or clash of cultures'? Journal of Interprofessional Care, 16 (3), 199-210 https://doi.org/10.1080/13561820220146649

Johnston, C. and Haughton, P. (2007) 'Teaching and learning ethics: Medical students' perceptions of their ethics teaching'. Journal of Medical Ethics, 33, 418-422 https://doi.org/10.1136/jme.2006.018010

Kenny, B. (2015) 'Food culture, preferences and ethics in dysphagia management'. Bioethics. Special Issue: International Association of Bioethics 12th World Congress 29, 9, 646652 https://doi.org/10.1111/bioe.12189

Kenny, B., Lincoln, M., and Balandin, S. (2010) 'Experienced speech-language pathologists' responses to ethical dilemmas: An integrated approach to ethical reasoning'. American Journal of Speech-Language Pathology, 19, 121-134 https://doi.org/10.1044/1058$\underline{0360(2009 / 08-0007)}$

Kenny, B., Lincoln, M., and Killian, F. (2015) 'Ethics cases: Do they elicit different levels of ethical reasoning'? Journal of Academic Ethics, 13 (3), 259-275 https://doi.org/10.1007/s10805-015-9234-6

Kinsella, E.A., Park, A.J.-S., Appiagyei J., Chang, E., and Chow, D. (2008) 'Through the eyes of students: Ethical tensions in occupational therapy practice'. Canadian Journal of Occupational Therapy, 75 (3), 176-183 https://doi.org/10.1177/000841740807500309

Kirklin, D. (2007) 'Minding the gap between logic and intuition: An interpretative approach to ethical analysis'. Journal of Medical Ethics, 33, 386-389 https://doi.org/10.1136/jme.2005.015156

Kulju, K., Suhonen, R., and Leino-Kilpi, H. (2013) 'Ethical problems and moral sensitivity in physiotherapy: A descriptive study'. Nursing Ethics, 20 (5), 568-577 https://doi.org/10.1177/0969733012468462 
Liaschenko, J., Oguz, N.Y., and Brunnquell, D. (2006) 'Critique of the "tragic case" method in ethics education'. Journal of Medical Ethics, 32, 672-677 https://doi.org/10.1136/ime.2005.013060

Maidment, J. (2006) 'Using on-line delivery to support students during practicum placements'. Australian Social Work, 59 (1), 47-55 https://doi.org/10.1080/03124070500449770

Mann, K., Gordon, J., and MacLeod, A. (2009) 'Reflection and reflective practice in health professions education: A systematic review'. Advances in Health Sciences Education, 14 (4), 595-621 https://doi.org/10.1007/s10459-007-9090-2

Numminen, O., van der Arend, A., and Leino-Kilpi, H. (2009) 'Nurses educators' and nursing students' perspectives on teaching codes of ethics'. Nursing Ethics, 16 (1), 69-82 https://doi.org/10.1177/0969733008097991

Pasco, J., Bay, U., and Courtney, M. (2010) 'You become the supervisor'. in Clinical and Fieldwork Placement in the Health Professions. ed. by Stagnitti, K., Schoo, A., and Welch, D. South Melbourne, Australia: Oxford University Press, 315-328

Pettifor, J.L., Estay, I., and Paquet, S. (2002) 'Preferred strategies for learning ethics in the practice of a discipline'. Canadian Psychology/Psychologie canadienne, 43 (4), 260 269 https://doi.org/10.1037/h0086922

Praestegaard, J. and Gard, G. (2013) 'Ethical issues in physiotherapy - Reflected from the perspective of physiotherapists in private practice'. Physiotherapy Theory and Practice, 29 (2), 96-112. https://doi.org/10.3109/09593985.2012.700388

Rowell, M. (1998) 'Feminist approaches to bioethics: Theoretical reflections and practical applications'. Journal of Medical Ethics, 24, 213-213 https://doi.org/10.1136/jme.24.3.213

Seedhouse, D. (2009) 'The background to the ethical grid'. in The Heart of Health Care. ed. by Seedhouse, D. Chichester, UK: Wiley-Blackwell, 142-174.

Self, D.J., Wolinsky, F.D., and Baldwin Jr., D.C. (1989) 'The effect of teaching medical ethics on medical students' moral reasoning'. Academic Medicine, 64, 755-759 https://doi.org/10.1097/00001888-198912000-00014

Sharp, H.M. and Kuthy, R.A. (2008) 'What do dental students learn in an ethics course? An analysis of student-reported learning outcomes'. Journal of Dental Education, 72 (12), 1450-1457

Smith, T., Williams, L., Lyons, M., and Lewis, S. (2005) 'Pilot testing a multiprofessional learning module: Lessons learned'. Focus on Health Professional Education: A Multi-Disciplinary Journal, 6 (3), 21-23

Spike, J.P. and Lundstroth, R. (2016) 'Framing interprofessional ethics cases'. in A Casebook in Interprofessional Ethics: A Succinct Introduction to Ethics for the Health Professions [online]. ed. by Spike, J.P. and Lundstroth, R. Switzerland: Springer International Publishing, 11-17 https://doi.org/10.1097/00001888-198912000-00014

Vergés, A. (2010) 'Integrating contextual issues in ethical decision making'. Ethics \& Behavior, 20 (6), 497-507 https://doi.org/10.1080/10508422.2010.521451 